\title{
Complex biliary stricture treated by percutaneous single-operator cholangioscopy and multiple biodegradable stents
}

The endoscopic treatment of biliopancreatic disease in patients with altered surgical anatomy is challenging [1]. A 42-year-old woman who had previously undergone a standard Whipple procedure surgery because of duodenal adenocarcinoma presented with multiple large biliary stones and a symptomatic benign stricture of the hepaticojejunal anastomosis, detected by magnetic resonance imaging. Double-balloon enteroscopy failed to reach the hepaticojejunal anastomosis and hybrid radiological/endoscopic treatment was decided upon.

First, a 7-Fr percutaneous biliary drain was placed ( Video 1 ). Two days later, a double-lumen, 11-Fr introductory catheter was placed and percutaneous singleoperator cholangioscopy-assisted electrohydraulic lithotripsy was carried out (SpyGlass DS, Boston Scientific, Marlborough, Massachusetts, USA) ( Fig. 1). Following stricture dilation to $13 \mathrm{~mm}$ (CRE, Boston Scientific), the fragmented stones were pushed into the lumen of the small bowel using an endoscopic retrograde cholangiopancreatography (ERCP) balloon. A new internal-external radiological drain was placed.

In a second session, the percutaneous drain was removed. A residual biliary stone ( $\triangleright$ Fig. 2) was gently pushed into the small bowel using a wire-guided anterograde balloon extractor. Thus, three 0.0035/0.0025-inch guidewires were placed through the hepaticojejunal stricture using the percutaneous tract ( Fig.3). Three 10-Fr, 6-cm biodegradable stents (Archimedes, Medtronic, Dublin, Ireland) with a slow profile (11 weeks for biodegradation) were placed in parallel in the hepaticojejunal stricture ( $\vee$ Fig.4), while the three guidewires were kept in place to allow repositioning if needed. A 7-Fr cannula was used as a pusher under radiological guidance. The patient was discharged $48 \mathrm{~h}$ later with no complications and no biliary symptoms at 1 -month follow-up.

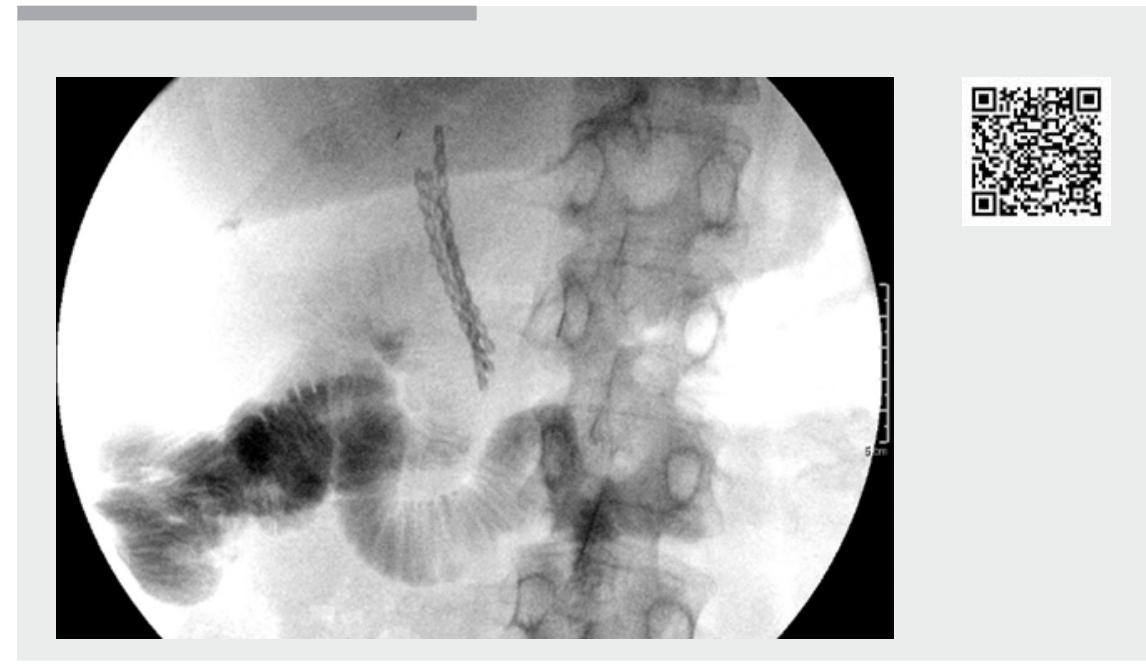

Video 1 A patient with previous Whipple surgery presented with biliary stones and a benign anastomotic stricture. Percutaneous single-operator cholangioscopy-assisted electrohydraulic lithotripsy was performed. Three biodegradable stents were placed.

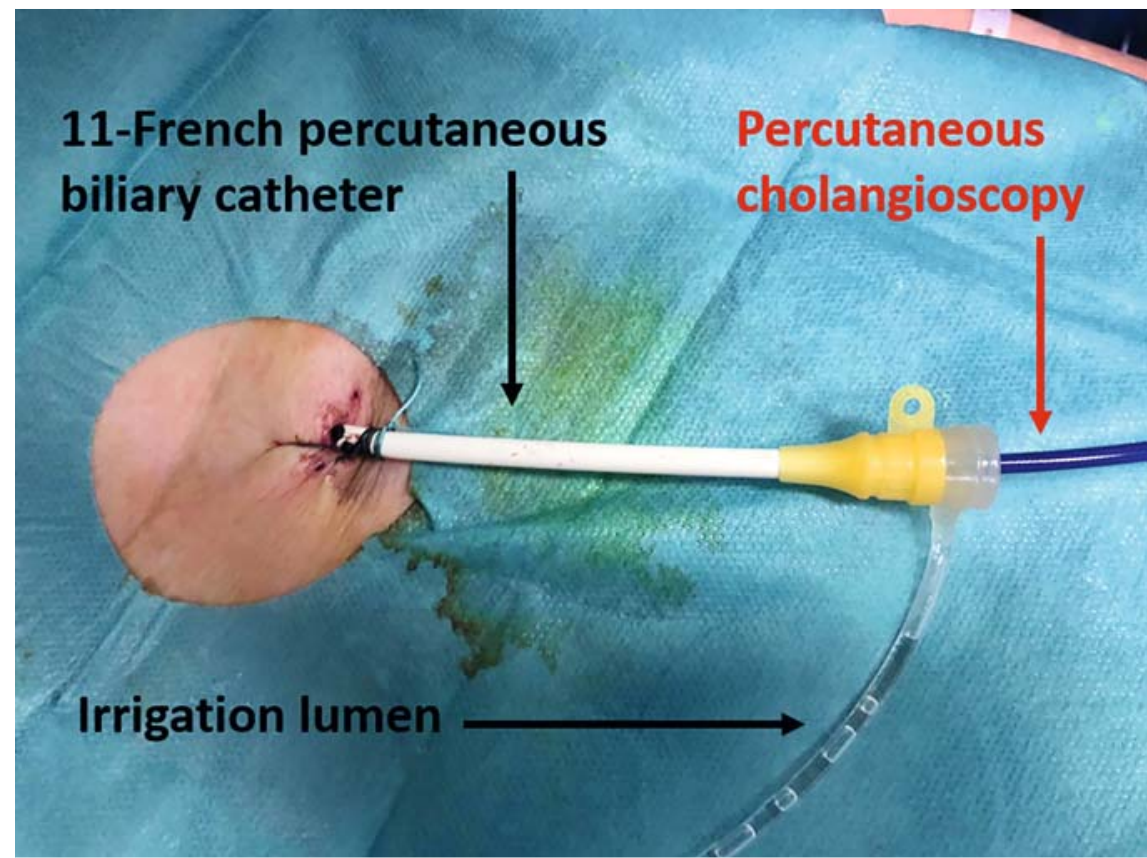

- Fig. 1 Percutaneous cholangioscopy-assisted electrohydraulic lithotripsy of large biliary stones through an $11-\mathrm{Fr}$ catheter in a patient with previous Whipple surgery.

Biodegradable biliary stents are a new alternative in the management of benign biliary strictures. These stents have a he- lical channel design and good fluoroscopic visibility [2]. Their main advantage is that they do not need to be ex- 


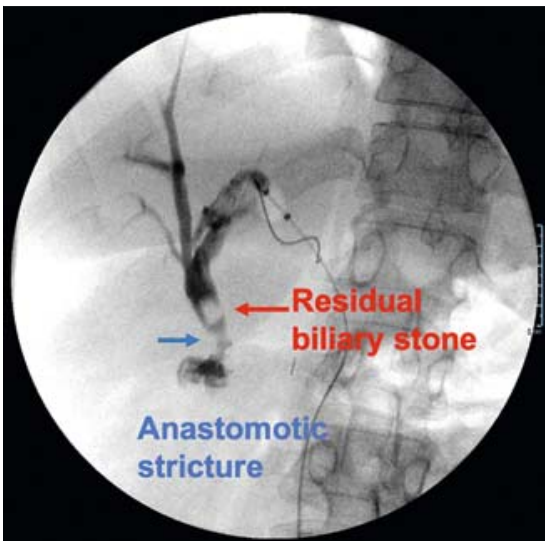

- Fig. 2 Residual biliary stone (red arrow) and stricture of the hepaticojejunal anastomosis (blue arrow).

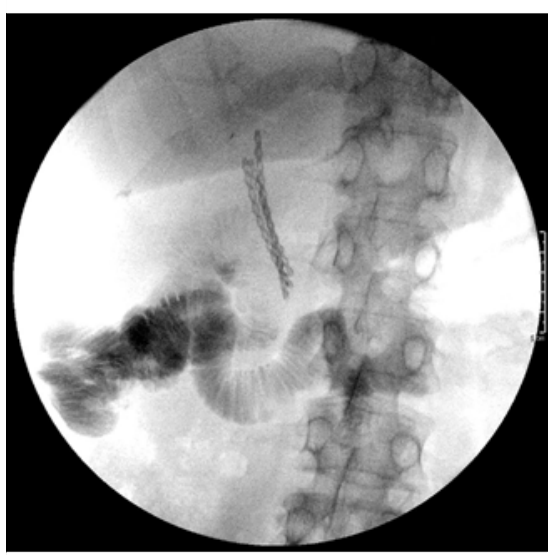

- Fig. 4 Radiological image of the three 10-Fr, 6-cm biodegradable stents successfully placed in parallel in the stricture of the hepaticojejunal anastomosis. The helical design is visible. Contrast is flowing into the small bowel.

changed. This feature can be extremely useful and can avoid more invasive procedures or major surgery in patients with altered surgical anatomy, as in the present case.

Endoscopy_UCTN_Code_TTT_1AR_2AJ

\section{Competing interests}

The authors declare that they have no conflict of interest.

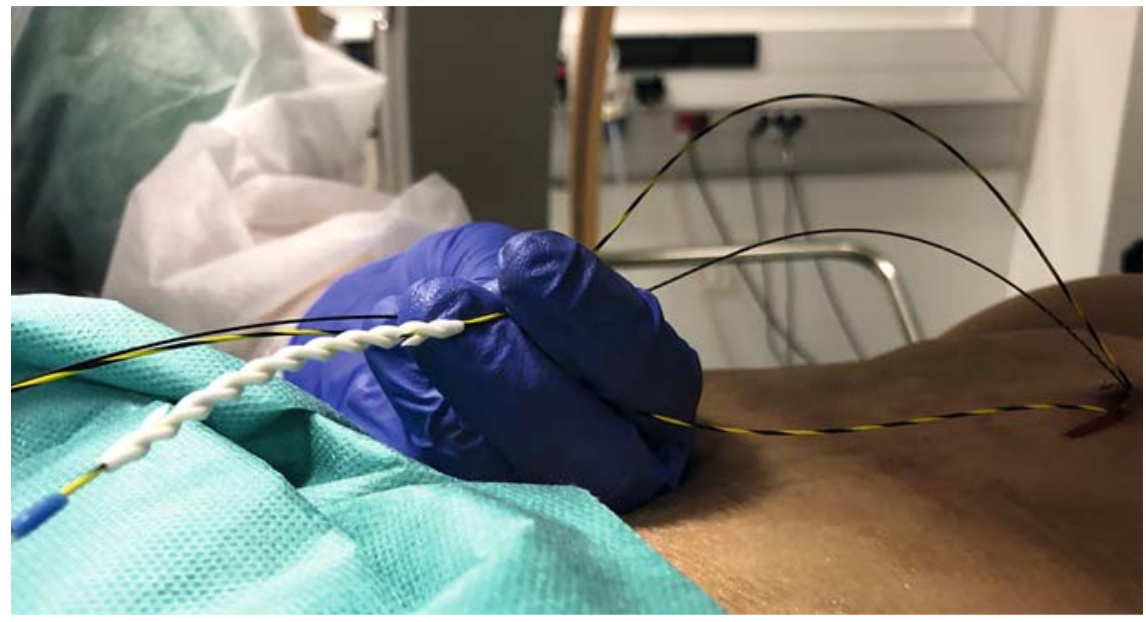

- Fig. 3 Three guidewires placed in the hepaticojejunal stricture using the previous percutaneous biliary drainage tract. A $10-\mathrm{Fr}$ biodegradable stent is visible.

The authors

Enrique Pérez-Cuadrado-Robles ${ }^{1}$, Guillaume Perrod ${ }^{1}$, Hedi Benosman ${ }^{1}$, Nadia Moussa ${ }^{2}$, Olivier Pellerin ${ }^{2}$, Christophe Cellier ${ }^{1}$, Gabriel Rahmi ${ }^{1}$

1 Department of Gastroenterology and Digestive Endoscopy, Georges-Pompidou European Hospital, AP-HP Centre Université de Paris, Paris, France

2 Department of Interventional Radiology, Georges-Pompidou European Hospital, APHP Centre - Université de Paris, Paris, France

Corresponding author

Enrique Pérez-Cuadrado-Robles, MD, PhD Department of Gastroenterology, Georges-Pompidou European Hospital, 20 Rue Leblanc, 75015 Paris, France kikemurcia@gmail.com

\section{References}

[1] James H], James TW, Wheeler SB et al. Costeffectiveness of endoscopic ultrasound-directed transgastric ERCP compared with device-assisted and laparoscopic-assisted ERCP in patients with Roux-en-Y anatomy. Endoscopy 2019; 51: 1051-1058

[2] Anderloni A, Fugazza A, Maroni L et al. New biliary and pancreatic biodegradable stent placement: a single-center, prospective, pilot study (with video). Gastrointest Endosc 2020; 92: 405-0411

\section{Bibliography}

Endoscopy 2021; 53: E255-E256

DOI 10.1055/a-1252-2764

ISSN 0013-726X

published online 23.9.2020

(c) 2020. Thieme. All rights reserved.

Georg Thieme Verlag KG, Rüdigerstraße 14, 70469 Stuttgart, Germany

\section{ENDOSCOPY E-VIDEOS}

https://eref.thieme.de/e-videos

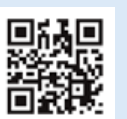

Endoscopy E-Videos is a free access online section, reporting on interesting cases and new techniques in gastroenterological endoscopy. All papers include a high quality video and all contributions are freely accessible online.

This section has its own submission website at https://mc.manuscriptcentral.com/e-videos 